\title{
Research Paper: The Youth and Experience of Traffic Accidents (Grounded Theory)
}

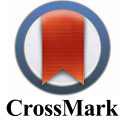

\author{
Sayyed Mohammad Hossein Javadi ${ }^{1}$, Siyamak Tahmasebi ${ }^{2}$, Tahere Azari Arghun ${ }^{3^{*}}$, Malihe Arshi ${ }^{1}$, Fardin Alipour
}

1. Department of Social Work, University of Social Welfare and Rehabilitation Sciences, Tehran, Iran.

2. Department of Preschool, University of Social Welfare and Rehabilitation Sciences, Tehran, Iran.

3. Iran Association of Social Workers, Tehran, Iran.

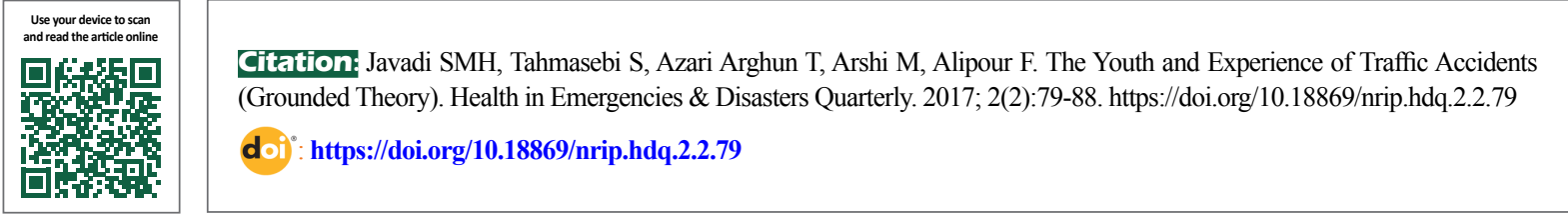

Article info:

Received: 30 May 2016

Accepted: 05 Aug. 2016

\section{Keywords:}

Traffic accident, Youth, Grounded theory

\section{ABSTRACT}

Background: Traffic accidents are among major causes of death all over the world. In Iran, it has become a social problem, with lots of people involved in; and the youth include the most victims of traffic accidents. The main objective of this research is to review the experience of the youth (18-24 years old in Tehran, Iran) with traffic accidents, and to develop a model to specify the factors.

Materials and Methods: This study is based on Grounded Theory, in which a sample group of 50 young people, 18-24 years old, in Tehran, Iran, were selected and interviewed, using stratified purposive and snowball sampling method. Data is mainly collected by interviewing the youth in 7 key topics. To analyze the data, Grounded Theory is used through production of themes, components and concepts.

Results: There are 11 general components for traffic accidents according to the ideas of the youth which will come in 3 categories including: individual factors (emotions, sensorymotor skills, and physical-mental health); environmental factors (road and traffic problems, a companion, using cellphone, or front individual, including carless drivers or passersby); and underlying factors (gender, legal and cultural infrastructures). And finally, the core category of carelessness, which is the leading cause in traffic accidents.

Conclusion: The findings indicate that a chain of various factors may cause traffic accidents with lots of devastating consequences. It is therefore necessary to modify driving culture, to internalize the attitude of caution, to use polyhedral strategies, and to apply them all correctly.

\section{Introduction}

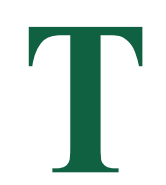

hough the rate of deaths caused by traffic accidents has been reduced in recent years, the figures still show the seriousness of the problem in society and force the authorities to take action in order to recognize and control the causes of such accidents. It is estimated that annually about 5 million people lose their lives in accidents and ten times more become disabled [12]. Traffic accidents are among the main causes of mortality in developing countries, the first cause of death for people less than 40 years, and the third one for all age groups which takes thousands of lives daily in roads. Traffic accidents 
not only kill healthy people in their best period of life in terms of performance, efficiency and wellbeing, but also impose great financial expenses, and psychological pains to the families [15]. The major components of traffic and transportation are human beings, roads, and vehicles, each with a role in causing traffic accidents. Different experiences in various countries show the share of human factor as $70 \%-80 \%$, which indicates the importance of paying more attention to this component among the others [3].

Theory of planned behavior is based on behavior and try to answer the question why drivers behave in a certain way. According to the theory of planned behavior, people's attitude towards their behaviors, subjective norms, and perceived behavioral control determine their intentions for taking that behavior [9]. This theory anticipates a certain behavior if the person is intended to take those behaviors. The intention for taking a behavior is accordingly anticipated by three factors: Attitude: his or her positive view towards taking a behavior; Social norms: his or her feeling about the social pressure for taking that behavior; and Perceived behavioral control: his or her feeling about his or her ability to take that behavior [1].

In Shope and Bingham model (2008) the influential factors are personality factors (willingness to take risks, aggressiveness, hostility, susceptibility to peer pressure, tolerance deviations, and irritability); behavioral factors (anti-social behavior, addiction, risk taking, conducting problems, driving prior to have certificate); growth factors (hormones, energy, sleep, psychosocial and emotional factors); social factors (identity, and sexuality); driving capabilities (knowledge, experience, skill); demographic factors (age, gender, employment, education, and living situation); environmental perception (parents' norms, expected behaviors, conflicts with parents, peer norms control, social norms, press propaganda, leisure time, hazard perception); driver's physical and social environment (night or darkness, road and climatic conditions, capability of vehicle, type of vehicle, companion's age, gender, and addiction, the objective of the trip) which influence the youth driving behaviors such as speed, unsafe overtaking, ignoring the permitted distance, risky driving, tiredness, distress, and not fastening seat belt [13].

According to Morrongiello and Lessard model (2007), personal characteristics (age, gender, behavioral attitudes, experiences, individual values and motivations, moods); family and parents (socialization practices, learning practices, parenting styles, sibilant impacts, parents' patterning); and social or situational factors (verbal encouragements, observational learning impacts, en- couraging motivational conditions) all interact to bring about risk taking or prevent an accident [8].

This study aimed to thoroughly identify and deeply review the issues related to traffic accidents from the point of view of youth who are the majority of the victims in traffic accidents; and finally to define a model based on social and psychological approach to be used by executive planners in order to reduce the traffic accidents.

\section{Materials and Methods}

\section{Research design}

The current study is an applied-developmental research in terms of its objective and a qualitative research in terms of its paradigm, and uses grounded theory in methodology.

\section{Study population and sampling}

Due to the scope of traffic accidents in Iran, and the importance of multifaceted view towards the issue, all qualified people aged 18-24 years (had traffic accidents in the last two years) were the study population. Since the participating population size in qualitative research is measured by saturation or adequacy of data, 63 young drivers with traffic accident experience were evaluated by self-designed semistructured interviews. Some interviews were distorted, so 50 ones were finally chosen. All participants in this phase were chosen by purposive and snowball sampling method.

\section{Measuring tools}

Data were collected using 14 questions in semi-structured interviews. The main questions from interviewees were focused on internal and external factors affecting the accident, environmental factors affecting the accident, his or her physical and mental conditions at the time of accident, the role of the other driver in the accident, his or her ideas about the traffic rules, the role of speed and trick-driving, qualities of a good driver, their sources for obtaining information and the quality of educating about traffic rules, youth leisure time, and the role of surrounding people in driving behavior change.

\section{Study procedure}

First the questionnaire got ready through the mentioned procedure. Then trial interviews were conducted. Next, the interviews were recorded by taking permission from legal, medical, law and insurance offices and authorities. All interviews were rechecked with interviewees after being transcribed. And finally all concepts, components, and themes were extracted. 
Table 1. Extensive categories and subcategories of concepts (axial coding)

\begin{tabular}{|c|c|c|c|}
\hline & Subcategories & Extended Categories & Categories \\
\hline 1 & Interest in speed & & \multirow{8}{*}{$\begin{array}{l}\text { Individual factors affecting traffic } \\
\text { accidents }\end{array}$} \\
\hline 2 & Interest in experience & Emotions & \\
\hline 3 & Show off & & \\
\hline 4 & Experience, skill & & \\
\hline 5 & Speedy action & Sensory-motor skills & \\
\hline 6 & $\begin{array}{c}\text { Physical and mental problems (tiredness, stress, ...) } \\
\text { Drug and alcohol }\end{array}$ & $\begin{array}{l}\text { Physical and mental } \\
\text { health }\end{array}$ & \\
\hline 8 & Carelessness & \multirow[b]{2}{*}{ Concentration } & \\
\hline 9 & Distraction & & \\
\hline 10 & Companion & Companion & \multirow{4}{*}{$\begin{array}{l}\text { Environmental factors affecting traffic } \\
\text { accidents }\end{array}$} \\
\hline 11 & Vehicle technical defect & & \\
\hline 12 & Road and traffic problems & $\begin{array}{l}\text { Road and traffic prob- } \\
\text { lems }\end{array}$ & \\
\hline 13 & Other party & Other party & \\
\hline 14 & Gender & Gender & \multirow{8}{*}{$\begin{array}{l}\text { Underlying factors affecting traffic } \\
\text { accidents }\end{array}$} \\
\hline 15 & $\begin{array}{l}\text { Accuracy of rules and monitoring their implementa- } \\
\text { tion }\end{array}$ & Rules & \\
\hline 16 & Driving license & & \\
\hline 17 & Education and training & \multirow{5}{*}{ Culture } & \\
\hline 18 & Leisure time & & \\
\hline & & & \\
\hline 19 & Family and friends & & \\
\hline 20 & Media (TV, radio, internet, sat, ...) & & \\
\hline
\end{tabular}

Hilealth in

Emergencies and |D]isasters [Oluarterly

\section{Results}

A total of 63 young drivers with traffic accident experiences were studied. Since some interviews were distorted, 50 interviews were chosen to be analyzed. The demographic characteristics of the participants will be given here.

About $26 \%$ of young participants were female and $74 \%$ male. Also, $43 \%$ of the participants had high school education, $32 \%$ guidance school, $13 \%$ bachelor degree, $5 \%$ associate degree, and the rest had just some school education. Most participants were over 21 years old. Also, most participants (about 34\%) were the eldest child of the family. More than half of the participants (58\%) did not have driving license. Most participants had more than 2 years of driving experience. About $81 \%$ of par- ticipants had just one traffic accident experience. Also, $56 \%$ of accidents have occurred during the daytime, and $44 \%$ during night. The traffic accidents that the drivers experienced and studied here were mostly car accidents.

Coding process in this study included 3 steps: open coding, core coding, and selective coding. In this step, sentences, which were previously coded, recombined to recognize the categories capable of connecting other categories or concepts and to form the research conceptual framework.

Data analysis passed through several stages in this study. In the first stage, namely open coding, 90 concepts were recognized. In the next stage (core coding), those concepts were reduced to 20 subcategories and 11 broad categories (Table 1); and in the selective coding, all cate- 
Table 2. Axial concepts and categories (selective coding)

\begin{tabular}{ccc}
\hline & Categories & Core Category \\
\hline 1 & Individual factors affecting traffic accidents & \\
2 & Environmental factors affecting traffic accidents & Carelessness \\
3 & Underlying factors affecting traffic accidents & \\
\hline & & |lealth in \\
& & Emergencies and [D]isasters [Oluarterly
\end{tabular}

gories were first divided into 3 major levels which led to the emergence of core category, i.e., carelessness (Table 2). Now research findings will be discussed here.

\section{Individual factors affecting traffic accidents:}

One of the most important factors mentioned by the interviewees were those related to individuals, which were placed in categories of emotions, sensory-motor skills, and physical-mental health.

\section{Emotions}

Emotions are considered as psychological issues, including concepts such as interest in speed, interest in experience, pride, and show off. Many participants mentioned these factors as major elements causing traffic accidents, especially among the youth.
“... time passes much slower, you feel everybody frozen, just like statues, and it's you all're watching”, remarked one interviewee about the experience of speed.

"Your experience makes you speedier, and shows you more experienced. The young go nuts and drive fast", mentioned another interviewee.

"The youth forget God and their family when driving". also "The youth are highly proud and believe they would never do wrong". said some interviewees indicating their pride.

\section{Sensory-motor skills}

In Figure 1, By sensory-motor skills, we mean a combination of skills such as concentration, precision, attention, and speed of action; mentioned directly or indirectly by interviewees.

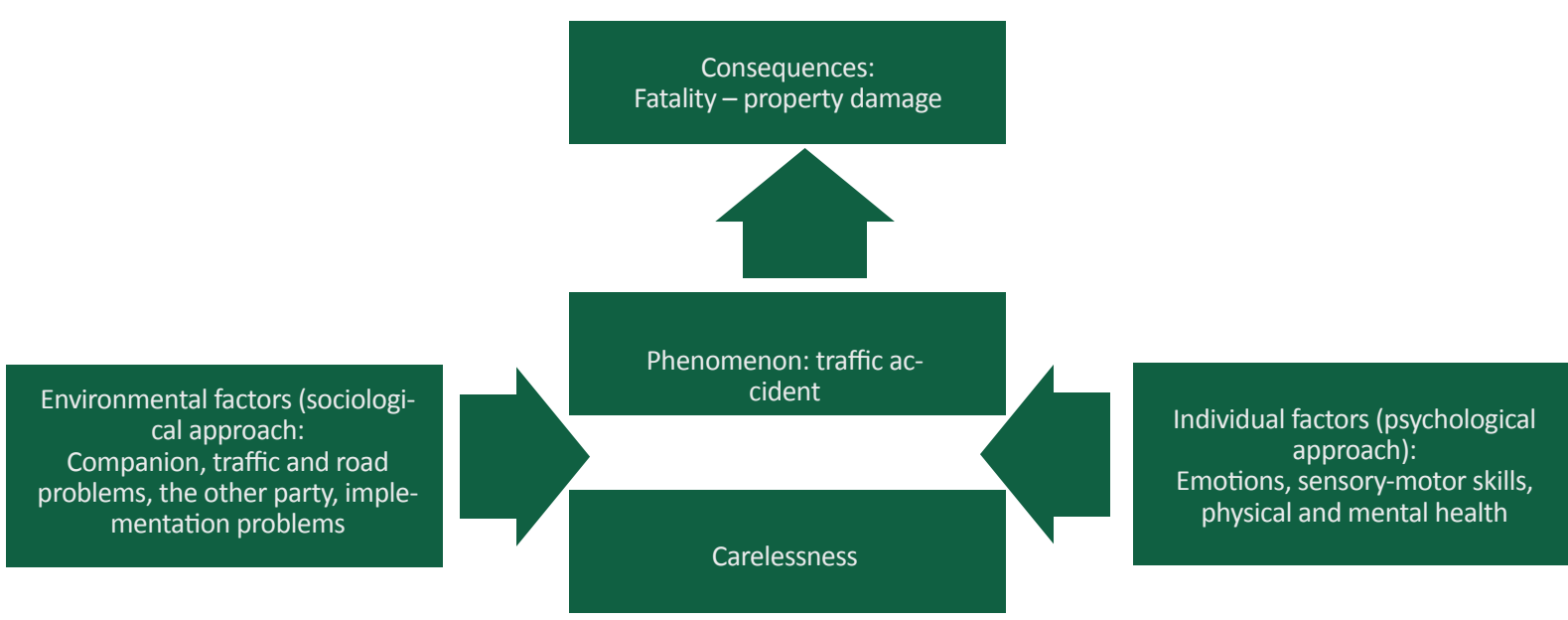

Health in

Emergencies and |D] isasters [Oluarterly

Figure 1. The underlying model of the youth experience in traffic accidents in Tehran with an emphasis on psycho-social approach 
"If only I paid more attention instead of talking to my companion. If I wasn't panicked; I wouldn't have crushed". said one of the participants.

The youth's attention may be easily diverted by some factors not under their control such as road scenery [2], or intentional ones such as smoking. Interactions with their younger companions may also divert the attention of younger drivers [2]. They may also be ignorant of the impacts of not paying full attention to driving [11]. There are lots of studies mentioning two factors of tiredness and distraction as main causes of traffic accidents [4].

\section{Physical and mental health}

Physical and mental health in this study includes concepts such as tiredness, drowsiness, sickness, anxiety, stress, and using drug and alcohol, which have a very critical role in the occurrence of accidents.

"When you're drunk, you never feel the danger, and you think there's no danger in having accidents", said an interviewee about driving after drinking alcohol.

Many interviewees mentioned tiredness, drowsiness, and weakness as the main reasons for their accidents. Tiredness and distraction have been indicated as main factors of accidents in lots of studies. Tiredness leads to distraction and lengthens reaction time of the drivers [4-7].

\section{Environmental factors affecting traffic accidents}

Those factors which are not related to individuals, but related to driving environment are categorized under the title of environmental factors affecting traffic accidents. These include road and traffic problems such as sharp hairpins, trenches, speed bumps, lack of traffic signs, and so on; companion, including a human or a cellphone; the other party, either another driver or a careless passerby.

\section{Road and traffic problems}

Many interviewees pointed to road and traffic problems as main factors in their own accidents.

"It was much better if I kept my way with no attention to rugged surface of the road". remembered one of the participants out of his accident.

"I believe that defects of driving are partly because of infrastructures, roads, flyovers, highways, and also cars with poor qualities", or "If there were enough bars on roadsides, nobody never thought of passing across the highways." said another interviewee.

\section{Companion}

By companion we mean both cellphone and an individual. There were different ideas about having companions; some believed having a good one would strengthen the attention and prevent distraction; yet some others took the opposite idea and considered the individual companion as a factor in occurring accidents. The third group believed that the presence of a good companion improves driver's performance. Following words reflect the ideas of these three groups.

"Being alone while driving lessens the possibility of any harm compared to having some companion", or "A companion helps you drive carefully", or "Having somebody with you helps not to feel bored or drowsy...", "Having companion is good just when he is of any help, not just talking and causing distraction".

Cairda et al. (2008) reported in their meta-analysis that using cellphone has effects on driver's performance and increases traffic accidents [14].

\section{Other party}

Other driver or careless passerby are the cause of many accidents, so that the driver himself/ herself had no role in the occurrence of the accident. Now some of interviewees' experiences are mentioned.

"I was driving in a highway in dark night; a passerby passed across the road while the pedestrian bridge was just 20 meters away; the other driver came from prohibited way; Wanna not to come over Peugeot, I tilted my motorcycle".

\section{Underlying factors affecting traffic accidents}

By underlying factors, those factors are meant that indirectly and through some underlying causes influence the traffic accidents indirectly. Three such factors were found from analyzing the obtained data; gender, legal infrastructures, and cultural factors.

\section{Gender}

There were controversies about the role of gender. Some believed that men are better and women are less skilled in driving.

"Men are more knowledgeable and experienced; women aren't good drivers; because they aren't skilled and subtle enough to drive in the roads". 
Some others believed that women are more law-abiding and cautious, so they have fewer accidents than men.

"Women more than men are interested in law, observe morality more and act better in subtleties of driving."

Yet some others saw no difference between men and women in driving.

"There is no place for gender in traffic accident; it is law-abiding that matters".

\section{Legal infrastructures}

Some executive problems of traffic laws such as monitoring, tickets, police presence, age of driving license, the quality of license centers, and the rules related to license are all here categorized as legal infrastructures. Male and female interviewees had different ideas about rules and regulations; men (but not women) mostly mentioned the items "tickets are not effective" and "regulations are not useful". It shows that male and female perceptions are different from each other, just similar to those previously observed in other studies. Females are more positive towards the rules and regulations, and as it is indicated in programed behavior theory, these perception and approach seems to influence driving behaviors of men and women, the rate of their accidents, and their risky attitudes. Most interviewees believed that the rules are good enough but there are some problems in their execution.

For example, "Rules are excellent; to have orders we have to obey them", said a female driver.

"Tickets are not effective in the long term; the police use tickets as a source of income, instead of directing the behavior; tickets cause fear; its overuse just increases the spirit of revenge".

Regarding the driver training and license center, an interviewee said:

"It's a good idea to have some places to answer questions related to traffic rules and regulations, and answering machines to give traffic figures and information to those in need". "Driver license centers are usually very crowded and costly. It's better to increase the number and quality of such centers", and "How good it can be if it comes to train students for driving in their curriculum", "Training that is provided in these centers focus more on giving licenses instead of real teaching, and this is not good and acceptable". believed another interviewee.
The number of years that a driver had his or her driving license is very important in car accidents. The people who are more experienced in driving, commit fewer driving violations compared to younger people [16]. Besides, younger people are more likely to have personality traits (like thrill- seeking), which comes along with risk-taking; this is consistent with the results of Zuckerman study (1980) [5].

\section{Cultural factors}

Culture is one of the most important factors affecting driving style, attitudes towards rules and regulations, and other phenomena, not in a direct way, but as an underlying and general factor. Lots of various items in the ideas of the interviewees were related to culture. Topics mentioned by interviewees in these study included media, teaching and training, family, school, peer groups, films, games, and youth leisure time. Many believed that the role of teaching and training is very influential.

"The youth don't observe the rules because they aren't familiar with them.... They should be taught from childhood", said an interviewee.

"People with rich cultural and economic viewpoints trust the laws even though there are some deficiencies in them", remarked another interviewee.

Other participants mentioned their ideas about the role of media "TV programs should show those experienced traffic accidents and now feel regretful", "Beautiful and top level actors have really great influence on their audience". "If the youth grow in a healthy family and be religious, they will surely observe the law". said an interviewee about the role of the family.

They considered an important role for peer groups, too. For example, "Bad friends pave the way for risky behaviors, alcohol, accidents, and many others". The youth leisure time is discussed by lots of professionals nowadays. The ideas of young participants in this study approved that lack of interesting and attractive programs for their leisure time plays a critical role in different issues, including traffic accidents. "We went for cycling just to enjoy our time and use our energy" or "There aren't enough good programs for the youth to enjoy".

\section{Core category}

Carelessness: The core category obtained from data analysis is "carelessness". All factors mentioned so far are some underlying causes for traffic accidents; yet this 
is the driver who plays the decisive role in preventing accidents by his or her sufficient information, considering all conditions, having the ability to predict, and adopt himself or herself to the situations. To be careful means to be attentive, mindful, cautious, prudent, and apprehensive. So a careful person considers existing situation and thinks about all consequences and outcomes. Accordingly, a careful driver considers all predictive measures such as the vehicle condition, weather condition, the road or highway condition where he or she is going to drive before starting his or her travel. Such a person is aware of his or her skills, emotions, physical and mental situation and knows all rules and regulations; so takes into account whatever may happen while driving.

Therefore, a careful driver thinks of all possible factors to reduce the probability of any accident. Drivers' carelessness is frequently the result of seeing danger far from himself or herself. The reason for high percentage of traffic accidents among the youth might be due to their lack of experience, being less cautious, and ignoring those factors which cause traffic accidents. From this point of view and considering carelessness as the core category, man is the only responsible factor in all traffic accidents. Of course, carelessness is not just an personal factor, but has some social aspects. A society capable of internalizing such a factor through education and culture making will surely influence all legislative and serving bodies and organizations, as well as car companies. Thus, we would see the better performance of these organizations in the long-run. Regarding these explanations, it seems that careful driving should become a part of the society culture; i.e., changes should happen in the infrastructures mentioned in this study.

\section{Design and validity of the model}

In this stage, data will be turned into a theory or model. After analyzing data, and connecting all various stages of the study, the research extract the theoretical model. The theoretical confirmation of the model by experts gave it validity.

\section{Discussion}

The study designed model, according to the sample, is related to the youth in Tehran. This model is actually the researcher's impression about the traffic accidents according to the opinions of young people in Tehran. In terms of statistics, Iran is among 5 top countries with the highest traffic accidents, and Tehran is among 3 first cities with traffic accidents.
Lots of studies have been conducted on various factors affecting traffic accidents. Yet most of them did not provide such a classification for this topic. In fact, in other models, all factors are considered at the same level, without considering their impact levels. However, as it is seen in the abovementioned model, three levels play roles in traffic accidents. The lowest level, i.e., underlying factors comprise the most infrastructure elements affecting on individual and environmental factors in the middle level; and the upmost level relates to human factors. Since human being is capable of controlling all conditions and elements, he or she is the final determinant. Needless to say that legislative bodies, law executors, and car companies play no role in this process. But it is meant that carefulness - with the meanings given - should be part of the culture, and be observed every moment and everywhere while driving on the roads, streets, and lanes, as well as in macro policy makings, in assembly lines of vehicle productions, in media, schools, driving schools, and so on. Caution and carefulness must be the priority not only in slogans but also in practice.

On the other hand, traffic accidents which have changed into a social problem in our country, cannot be solved just through procedural study of individual and social factors. Because, these factors, per se, are actually derived from some other factors which their broad expansions are much larger and deeper than direct influential factors.

Therefore, besides focusing on direct factors, it is much better to consider the importance of underlying causes in decision- and policy-making, more than ever. The most important ones are those related to legal infrastructures and, especially to culture. Policies implemented in rules and regulations during recent years have their own weak and strong points and were mentioned in the words of interviewees in this very study. Generally, law enforcement control and monitor has significantly improved, yet sufficient regularity and continuity is not seen in this monitoring. In other words, it seems that in some specific periods, and according to some circumstances, police monitoring are executed which bewilders the citizens and reduces their orderliness in observing the rules and regulations. Similar to our study results, other studies show that individual attitudes towards rules and regulations, traffic violations, controlling tools, individual attitudes towards his or her future, and also informal norms; individual knowledge of traffic rules, as the cultural subsystem of a society in the field of driving have a relation with the rate of traffic accidents [10]. 
As it was mentioned, by culture, we mean those factors such as family, school, peer groups, education and information, media, and the youth leisure time. Since this study just reviewed the youth's experiences of traffic accidents, there was no place for discussing and analyzing the underlying causes for each of these factors. However, it seems that each of these factors can be studied in a separate study. For example, one can study what are taught in this regard in schools. What is the role of media in this regard? And the youth's leisure time is one of the most important, and unfortunately almost ignored one in this regard.

Generally, various factors like a chain provide the ground for a traffic accident and its devastating consequences. Accordingly, to reduce traffic accidents, modify driving culture, and internalize cautious approaches, multifaceted strategies must be considered and executed correctly and professionally.

This essay is a qualitative part of a larger study entitled "Designing and implementing psycho-social interventions to reduce risk factors of traffic accidents among teenagers and the youth in Tehran" supported by UNICEF and Red Crescent Society. Based on the study results, many young people use driving, its risky type, to discharge their energies and spend their recreation time. Although some measures have been taken in this regard, such as preparing track racing, motorbike racing, and so on, there are some problems like accessibility to suitable programs for recreation activities, their suitable costs, and most importantly, their compatibility with human genetically-driven needs. By genetically-driven needs in psychological topics, we mean 5 fundamental needs: 1) survival, 2) love, 3) power, 4) fun, and 5) freedom [6]. It is better to account proportionally for these needs in planning for free-time of the young. In addition, the socioeconomic condition of the society must be considered.

\section{Conclusion}

On the whole, as can be seen, several associated factors pave the way for traffic accidents and their destructive consequences. Therefore, it seems that to reduce car accidents, correction of driving culture, internalizing the caution attitude, and multifaceted strategies must be considered and be executed correctly and by considering expert opinions. Also, as regard to beliefs like "there are no effective or preventive laws," "these laws are not executed," or "they can be ignored" among young people, laws must be up-to-dated in shorter time periods and based on field studies and be educated sufficiently. Finally, creating culture for educating caution, order and observing regulations must be regarded continuously and consistently since the young ages in schools and then at universities.

\section{Acknowledgements}

We express our gratitude towards the UNICEF representative in Iran and Red Crescent Youth Organization for financial supporting this research.

\section{Conflict of Interest}

The authors declare that there is no conflict of interests.

\section{References}

[1] Ajzen I. The theory of planned behavior. Organizational Behavior and Human Decision Processes. 1991; 50(2):179-211. PMID: 21929476

[2] Al-Hemoud A, Rodney M, Simmons J, Al-Asfoor M. Behavior and lifestyle characteristics of male Kuwaiti drivers. Journal of Safety Research. 2010; 41(4):307-13. doi: 10.1016/j. jsr.2010.06.001

[3] Barriri M, Bar-Soltan R. [Psychology of traffic (Persian)]. Tehran: Mehr Publishing; 2010.

[4] Carlson NR. Foundations of physiology and psychology. $7^{\text {th }}$ ed. Boston, Mass: Pearson; 2008

[5] Zuckerman M, Neeb M. Demographic influences in sensation seeking and expressions of sensation seeking in religion, smoking and driving habits. Personality and Individual Differences. 1980; 1(3):197-206. doi: 10.1016/0191-8869(80)90051-3

[6] Glasser W. Choice theory: An introduction to psychology of hope [A. Sahebi Persian trans]. $2^{\text {nd }}$ ed. Tehran: Saye-ye Sokhan; 2012.

[7] Javadi SM, Fekr Azad H, Tahmasebi S, Rafiei H, Rahgozar M, Tajlili A. Study of psycho-social factors affecting traffic accidents among young boys in Tehran. Iran Red Crescent Medical Journal. 2015; 17(7):22080. doi: 10.5812/ircmj.22080v2

[8] Morrongiello BA, Lasenby-Lessard J. Psychological determinants of risk taking by children: an integrative model and implications for interventions. Injury Prevention. 2007; 13(1):20-5. doi: 10.1136/ip.2005.011296

[9] Ozkana T, Lajunena T, Gruyola BD, Yıldırıma Z, Oymakb AC. Motorcycle accidents, rider behaviour, and psychological models. Accident Analysis and Prevention. 2012; 49, 124-132. doi: 10.1016/j.aap.2011.03.009

[10] Rahmani Firoozjah A, Abbasi Esfajir AS. Sociological Study of the causes of road accidents (Public road drivers of Babol) (Persian)]. Journal of Social Sciences. 1(1):177-94.

[11] Rosenbloom, T. Wultz, B. Thirty-day self-reported risky driving behaviors of ADHD and non-ADHD drivers. Accident Analysis and Prevention. 2011; 43(1):128-133. PMID: 21094306 
[12] Sanaee-Nasab H, Irani Gh, Raf'ati-Shaldehi H, Karimi A. [Prevalence of and risk factors of road accidents in a military center in Tehran (Persian)]. Journal of Management in Law Enforcement. 2008; 4(1):19-30.

[13] Shope JT, Bingham R. Motor-vehicle crashes and factors that contribute. American Journal of Preventive Medicine. American Journal of Preventive Medicine. 2008; 35(3):261271. doi: 10.1016/j.amepre.2008.06.022

[14] Cairda JK, Willness CR, Steel P, Scialfa C. A meta-analysis of the effects of cell phones on driver performance. Accident Analysis and Prevention. 2008; 40(4):1282-1293.

[15] World Health Organization. Global status report on road safety 2013: Supporting a decade of action. Geneva: World Health Organization; 2013.

[16] Shinar D, Tractinsky N, Compton R. Effects of practice, age, and task demands, on interference from a phone task while driving. Accident Analysis \& Prevention. 2005; 37(2):315-326. PMID: 15667818 
